\title{
MADEIRA SERRADA COMERCIALIZADA EM DOIS MUNICÍPIOS DO ESTADO DE MATO GROSSO
}

Bruno Domingos Pacheco ${ }^{1}$, Zaira Morais dos Santos Hurtado de Mendoza ${ }^{2}$, Pedro Hurtado de Mendoza Borges ${ }^{3}$, Maísa Pavani dos Santos Elias ${ }^{4}$,

Daniela Magali dos Santos 5 .

${ }^{1}$ Bacharel em Engenharia Florestal da Universidade Federal de Mato Grosso (UFMT), Cuiabá - MT, Brasil.

${ }^{2}$ Professora Doutora do curso de Engenharia Florestal da Universidade Federal de Mato Grosso (UFMT), Cuiabá - MT, Brasil.

E-mail: zairamorais09@gmail.com

${ }^{3}$ Professor Doutor do curso de Agronomia da Universidade Federal de Mato Grosso (UFMT), Cuiabá - MT, Brasil.

${ }^{4}$ Técnica em Laboratório, Doutora em Ciências da Saúde da Universidade Federal de Mato Grosso (UFMT), Cuiabá - MT, Brasil.

${ }^{5}$ Mestranda em Ciências Florestais e Ambientais da Universidade Federal de Mato Grosso (UFMT), Cuiabá - MT, Brasil.

\section{Recebido em: 04/10/2019 - Aprovado em: 30/11/2019 - Publicado em: 15/12/2019} DOI: 10.18677/EnciBio_2019B38

O estudo teve como objetivo fazer um levantamento quantitativo, sobre a comercialização de madeira serrada nos municípios de Chapada dos Guimarães e Cuiabá - MT, com intuito de buscar informações sobre o perfil das empresas, espécies utilizadas, volume de madeira comercializado, usos das madeiras e tipos de resíduos gerados. A coleta de dados foi feita com a aplicação de questionário "in loco", na forma de entrevista individual com os representantes de cada empresa. Ao todo foram entrevistados dez estabelecimentos madeireiros, sendo três em Chapada dos Guimarães e sete em Cuiabá. Os dados foram organizados em planilhas eletrônicas Excel e os resultados foram dispostos em tabelas e gráficos. Após análise dos resultados foi verificado que os perfis dos comércios de madeiras serradas nos municípios estudados foram semelhantes, caracterizado por empresas familiares que passam de geração em geração. Foram registradas 14 espécies comercializadas, sendo $85 \%$ provenientes de floresta nativa e $15 \%$ provenientes de florestas plantadas. As espécies mais comercializadas foram Cupiúba, Peroba, Itaúba e Cedrinho. Os principais usos das madeiras comercializadas foram respectivamente para a construção civil, indústria moveleira e construções rurais. A madeira serrada mais cara foi a Itaúba, tanto para compra quanto para venda. $O$ volume médio total de madeira serrada comercializada, nos estabelecimentos dos dois municípios foi de $355,0 \mathrm{~m}^{3} /$ mês para compra e de $325,0 \mathrm{~m}^{3} / \mathrm{mês}$ para venda. A serragem e a maravalha foram os resíduos gerados em maior quantidade, os quais eram vendidos para terceiros, que os utilizavam em artesanatos e na geração de energia em cerâmicas.

PALAVRAS-CHAVE: Espécies florestais, indústria madeireira, resíduos. 


\title{
SAWN WOOD COMMERCIALIZED IN TWO MUNICIPALITIES OF THE STATE OF MATO GROSSO
}

\begin{abstract}
The aim of this study was to do a quantitative survey on commercialization of lumber in the municipalities of Chapada dos Guimarães and Cuiabá - MT, to obtain information concerning profile of the establishments, species used, volume of wood sold, types of residues generated, and the main uses of wood. Data collection was performed by applying an on-site questionnaire in the form of an individual interview with the representatives of each company. Ten logging establishments were interviewed withthree establishments localized in Chapada dos Guimarães and seven in Cuiabá. The data were organized in Excel spreadsheets and the results were arranged in tables and graphs. After analysis of the results, it was verified that the profile of the lumber trade in the both municipalities was similar. The establishments were classified as family businesses and it has been passed through generations Forteen commercialized species were recorded, being $85 \%$ from native forest and $15 \%$ from planted forests. The most commercialized species were Cupiúba, Peroba, Itaúba and Cedrinho. The main uses of commercialized timber are for construction, furniture industry and rural buildings. The most expensive lumber was Itaúba, both for purchase and for sale. The total average volume of lumber sold in the establishments was $355.0 \mathrm{~m}^{3} /$ month for purchase and $325.0 \mathrm{~m}^{3} /$ month for sale, in both municipalities. Sawdust and wood shavings were the most generated waste by establishments. The most of this waste generated are sold to third parties, who use them in handicraft and in ceramics for energy generation.
\end{abstract}

KEYWORDS: Forest species, timber industry, residues.

\section{INTRODUÇÃO}

A indústria madeireira é um importante segmento que gera empregos e rendas nos países que investem neste setor. Seus produtos são utilizados em diversas atividades, como na construção civil. É uma atividade cuja matéria prima é retirada de florestas e, quando não realizada de maneira consciente, é altamente prejudicial, causando impactos ambientais e sociais (RAMOS et al., 2017).

No estado de Mato Grosso e em outros estados que possui o bioma Amazônia, a atividade madeireira teve início com a migração de madeireiros de outras partes do Brasil e ocorreu devido a incentivos do governo, com a abertura de estradas, a partir da década de 60, e com a escassez dos recursos madeireiros das regiões Sul e Sudeste.

O setor florestal madeireiro tem grande importância na economia do Brasil. Segundo o Instituto Brasileiro de Geografia e Estatística - IBGE (2016), a produção de madeira em tora originária de florestas nativas no Brasil, neste mesmo ano, totalizou $11.450 .693 \mathrm{~m}^{3}$ e destes, 3.324.051 $\mathrm{m}^{3}$ correspondem a Mato Grosso, sendo a região norte do estado a grande produtora de madeira serrada.

O volume de madeira comercializada em Mato Grosso é significativo e nos anos de 2016 e 2017 foram exportados cerca de $205.655 \mathrm{~m}^{3}$ na forma de madeira in natura (toras), madeira serrada, palanques, postes, madeira beneficiada, dormentes, madeira laminada faqueada ou torneada e madeira compensada (CIPEM, 2017).

Com a crescente demanda por madeira serrada nos últimos anos, o estudo da 
cadeia produtiva madeireira é de fundamental importância para a melhor gestão do setor. Apesar da grande importância da madeira no mercado nacional, poucos trabalhos abordam os perfis das empresas que comercializam madeiras serradas de espécies nativas. Diante do exposto, o presente estudo teve como objetivo realizar um levantamento quantitativo sobre a comercialização de madeira serrada nos municípios de Chapada dos Guimarães e Cuiabá - MT, com intuito de buscar informações sobre o perfil das empresas, as espécies utilizadas, o volume de madeira comercializado, os principais usos das madeiras, os tipos de resíduos gerados bem como sua destinação.

\section{MATERIAL E MÉTODOS}

\section{Localização e caracterização da área de estudo}

O presente estudo foi desenvolvido em estabelecimentos que realizam a comercialização de madeira serrada, nos municípios de Chapada dos Guimarães e Cuiabá, ambos no estado de Mato Grosso. A cidade de Chapada dos Guimarães encontra-se a uma latitude 15 $27^{\prime} 38^{\prime \prime}$ Sul e longitude $55^{\circ}$ 4' 59" Oeste e Cuiabá situa-se a uma latitude $15^{\circ} 35^{\prime}$ 56" Sul e longitude $56^{\circ} 06^{\prime}$ 05" Oeste. (IBGE, 2018). As empresas escolhidas localizam-se em diferentes regiões dentro dos municípios.

\section{Coleta de dados}

Para o levantamento das informações foram visitadas empresas que se auto denominaram marcenarias, madeireiras e lojas de materiais para construção, no período de dezembro de 2018 a janeiro de 2019. Ao todo foram escolhidas de forma aleatória dez empresas, sendo três em Chapada dos Guimarães e sete em Cuiabá.

Antes da entrevista e da assinatura do termo de consentimento para a coleta de dados, os participantes foram informados quanto ao objetivo da pesquisa e sobre o anonimato dos dados deles e de seus empreendimentos.

Em seguida, aplicou-se "in loco" um questionário na forma de entrevista individual, o qual abordava os seguintes tópicos: dados gerais sobre a empresa, informações específicas para cada espécie de madeira comercializada, principal uso da madeira, origem da madeira, volume de madeira recebido, usos e tipos de peças serradas, resíduos gerados e sua destinação.

Após a coleta, os dados foram processados em planilhas eletrônicas do Microsoft Office Excel e os resultados foram organizados em tabelas e gráficos.

\section{RESULTADOS E DISCUSSÕES}

Todos os estabelecimentos entrevistados, tanto no município de Chapada dos Guimarães quanto em Cuiabá, foram caracterizados como empresas familiares sendo o ofício repassado de pai para filho. Em ambos os municípios, as madeiras encontradas nos estabelecimentos estudados estavam na forma de peças secundárias e eram provenientes de toras que foram processadas em serrarias no próprio local de extração das madeiras. As peças processadas chegavam até os estabelecimentos por meio terrestre em rodovias. Conforme relatório do CNT (2018), no Brasil, o deslocamento por rodovias é responsável por mais de $60 \%$ do transporte de todos os tipos de cargas.

Nenhum dos entrevistados desdobravam toras, contudo, alguns afirmaram que quando necessário, eles realizavam o desdobro das peças maiores em peças menores, a pedido do cliente. 


\section{Origem da madeira serrada}

Quanto a origem, $70 \%$ das empresas declararam receber madeira de floresta nativa oriunda de manejo sustentável, $20 \%$ alegaram receberem de floresta nativa não manejada e 10\% alegaram receber de floresta plantada e manejada. Silgueiro et al. (2018) mapeando a ilegalidade da madeira de espécies nativas comercializadas no estado de Mato Grosso, no período de 2014 a 2016, verificaram que $67 \%$ do total da exploração era de origem legal no estado, e destas, 93\% ocorreram a partir de planos de manejo florestal sustentável.

A existência no comércio, de madeiras provenientes de florestas naturais não manejadas, pode estar associada a alguns fatores, pois segundo Ramos et al. (2017), os principais empecilhos para a adoção do manejo florestal em florestas nativas são problemas fundiários, escassez de informação sobre manejo para os empresários, falta de treinamento, informalidade no setor e o alto custo da operação de manejo.

\section{Volume de madeira comercializado}

O volume médio de compra de madeira na cidade de Chapada de Guimarães foi de $55,0 \mathrm{~m}^{3} / \mathrm{mês}$ e o consumo foi de $45,0 \mathrm{~m}^{3} / \mathrm{mês}$, já em Cuiabá o volume de compra foi de $300,0 \mathrm{~m}^{3} / \mathrm{mês}$ e o consumo de $280,0 \mathrm{~m}^{3} / \mathrm{mês}$, ficando um estoque de $10,0 \mathrm{~m}^{3} / \mathrm{mês}$ em Chapada e de 20,0 m³/mês em Cuiabá (Tabela 1). Entretanto, não foi possível obter o volume por espécie, uma vez que os entrevistados não tinham essa informação de forma segura.

TABELA 1. Volume mensal de madeira comercializado pelos estabelecimentos.

\begin{tabular}{ccc}
\hline \multirow{2}{*}{ Local/ Empresa } & \multicolumn{2}{c}{ Volume de madeira } \\
\cline { 2 - 3 } & Recebido $\left(\mathbf{m}^{\mathbf{3} / \mathbf{m e ̂ s}} \mathbf{)}\right.$ & Vendido $\left(\mathbf{m}^{\mathbf{3}} \mathbf{\mathbf { m e ̂ }} \mathbf{)}\right)$ \\
\hline Chapada/1 & 10,0 & 10,0 \\
Chapada/2 & 20,0 & 20,0 \\
Chapada/3 & 25,0 & 15,0 \\
\hline Subtotal & 55,0 & 45,0 \\
\hline Cuiabá/1 & 10,0 & 10,0 \\
Cuiabá/2 & 80,0 & 80,0 \\
Cuiabá/3 & 30,0 & 25,0 \\
Cuiabá/4 & 10,0 & 10,0 \\
Cuiabá/5 & 60,0 & 50,0 \\
Cuiabá/6 & 40,0 & 40,0 \\
Cuiabá/7 & 70,0 & 65,0 \\
\hline Subtotal & 300,0 & 280,0 \\
\hline TOTAL & 355,0 & 325,0 \\
\hline
\end{tabular}

\section{Informações sobre as espécies madeireiras}

Ao todo foram registradas 13 espécies florestais comercializadas, sendo 11 espécies de florestas nativas ( $85 \%$ do total) e 2 espécies de florestas plantadas (15\% do total). Além das espécies florestais, os estabelecimentos também comercializavam madeira reconstituída (mista). Verifica-se que grande parte do comércio de madeira serrada é abastecido com material proveniente de florestas nativas (Tabela 2). 
TABELA 2. Espécies encontradas nos estabelecimentos estudados.

\begin{tabular}{lllccc}
\hline Família & Espécie & Nome Vulgar & Chapada & Cuiabá & Total \\
\hline Celastraceae & Goupia glabra & Cupiúba & 2 & 5 & 7 \\
Vochysiaceae & Qualea sp. & Cambará & 2 & 0 & 2 \\
Burseraceae & Trattinickia sp. & Amescla & 0 & 1 & 1 \\
Meliaceae & Cedrela spp. & Cedro & 0 & 2 & 2 \\
Lauraceae & Mezilaurus itauba & Itaúba & 2 & 4 & 6 \\
Apocynaceae & Aspidosperma spp. & Peroba & 3 & 4 & 7 \\
Sapotaceae & Micropholis venulosa & Curupixá & 0 & 1 & 1 \\
Lauraceae & Nectandra robusta Loefl & Canelão & 0 & 1 & 1 \\
Vochysiaceae & Erisma uncinatum & Cedrinho & 3 & 4 & 7 \\
Lamiaceae & Tectona grandis & Teca & 2 & 0 & 2 \\
Fabaceae & Apuleia sp. & Garapeira & 0 & 1 & 1 \\
Fabaceae & Hymenaea courbaril L & Jatobá & 0 & 1 & 1 \\
Pinnaceae & Pinus spp. & Pinus & 0 & 1 & 1 \\
- & - & Mista & 0 & 3 & 3 \\
\hline
\end{tabular}

O município de Cuiabá comercializou mais espécies florestais do que o município de chapada dos Guimarães. Contudo, independente do município, as espécies mais comercializadas foram a Cupiúba, Peroba, Itaúba e Cedrinho, as quais possuem características tecnológicas muito apreciadas pelo setor madeireiro. Resultados semelhantes foram encontrados por Ribeiro et al. (2016) onde constataram que as 10 espécies mais comercializadas em ordem decrescente, pelo estado de Mato Grosso no período de 2004 a 2010, em termos de volume, foram Qualea sp. (Cambará), Goupia glabra (Cupiúba), Erisma uncinatum (Cedrinho), Mezilaurus itauba (Itaúba), Hymenolobium sp. (Angelim), Apuleia sp. (Garapeira), Manilkara sp. (Maçaranduba), Cordia goeldiana (Freijó), Dipteryx sp. (Cumbaru) e Trattinickia sp. (Amescla). Destaca-se o surgimento da Peroba como uma das mais vendidas e que não aparece no trabalho de Ribeiro et al. (2016).

Em menor escala, os estabelecimentos comercializaram Garapeira, Cambará, Curupixá, Jatobá, Amescla, Canelão, Cedro, Teca, Pinus e Madeira Mista. Essa última, caracteriza-se como uma mistura de várias espécies, geralmente de sobras de madeira após o desdobro na marcenaria e/ou serraria, que são unidas e reaproveitadas. Esse subproduto apresentou um preço menor em relação às outras madeiras, porém, ainda é pouco conhecido pelos consumidores.

Das espécies exóticas plantadas, apenas o Pinus spp. (Pinus), e a Tectona grandis (Teca), foram encontradas para comercialização, sendo utilizadas normalmente para carpintaria e marcenaria. A Teca é uma espécie muito valorizada para produção de peças de usos nobres e móveis finos, enquanto o Pinus, por ser uma madeira mais leve e de ótima usinagem, é utilizado para caixotaria, fundos de móveis, estofados e artefatos. Nesse estudo não foi verificado a comercialização de madeira de eucalipto, apesar de ser uma espécie amplamente plantada em nosso país. Isso provavelmente ocorreu devido à dificuldade no desdobro das toras dessa espécie, pois a mesma apresenta muita tensão de crescimento e uma baixa estabilidade dimensional. Além disso o eucalipto é uma espécie versátil e na região centro oeste está sendo utilizada basicamente para geração de energia, com 
diâmetros menores e em um ciclo curto de colheita, já para serraria ela teria que apresentar diâmetro de tronco maior e consequentemente ciclos longos de corte.

\section{Procedência das espécies madeireiras}

$\mathrm{Na}$ Tabela 3, encontram-se os municípios de Mato Grosso que forneceram madeira serrada para os estabelecimentos dos municípios estudados.

TABELA 3. Origem das madeiras serradas vendidas nos estabelecimentos.

\begin{tabular}{clc}
\hline Municípios estudados & Origem das madeiras & Empresas receptoras \\
\hline \multirow{3}{*}{ Chapada dos Guimarães } & Colniza & 3 \\
& Feliz Natal & 3 \\
& Nova Maringá & 2 \\
\hline & Aripuanã & 1 \\
& Brasnorte & 1 \\
& Cotriguaçu & 1 \\
Cuiabá & Itanhangá & 1 \\
& Juara & 1 \\
& Juína & 1 \\
& Marcelândia & 1 \\
\hline
\end{tabular}

Os estabelecimentos participantes da pesquisa receberam madeira de 11 municípios do estado de Mato Grosso, todos pertencentes à região da Amazônia Legal. Os municípios com a maior participação no fornecimento de madeira foram Feliz Natal e Colniza (que correspondem a 27,27\% do total de municípios fornecedores para Chapada dos Guimarâes) e Juína (que correspondem a 18,18\% do total de municípios fornecedores para Cuiabá). Nova Maringá também teve boa participação no fornecimento de madeira para o município de chapada dos Guimarães (18,18\%), já em Cuiabá, os municípios de Aripuanã, Brasnorte, Cotriguaçu, Itanhangá, Juara, Marcelândia e Porto dos Gaúchos, tiveram uma participação menor (9,09\%). Foi verificado também, que Cuiabá apresentou um maior número de municípios fornecedores em comparação com Chapada dos Guimarães, sendo inclusive distintos um dos outros.

Segundo Silgueiro et al. (2018), os seis municípios que mais exploraram madeira em Mato Grosso de 2013 a 2016 foram Aripuanã, Colniza, Feliz Natal, Juara, Nova Maringá e União do Sul. O mesmo autor ressalta, também, que o estado no ano de 2016, apresentou uma produção anual média de 3,4 milhões de $\mathrm{m}^{3}$ de madeira em tora, atendendo, em madeira serrada, $32 \%$ do mercado consumidor mato-grossense, $54 \%$ dos outros estados e $14 \%$ do mercado externo.

\section{Preço da madeira serrada}

De forma geral os valores mercadológicos das madeiras serradas oscilou bastante nos dois municípios estudados (Tabela 4 e 5).

TABELA 4. Valores mercadológicos de madeiras serradas comercializadas individualmente, conforme o município e a espécie florestal.

\begin{tabular}{|c|c|c|c|c|c|}
\hline \multirow{2}{*}{ Município } & \multirow{2}{*}{ Espécie } & \multicolumn{2}{|c|}{ Valores (R\$) } & \multirow{2}{*}{$\begin{array}{c}\text { Receita } \\
\text { (R\$) }\end{array}$} & \multirow{2}{*}{$\begin{array}{c}\text { Lucro } \\
(\%)\end{array}$} \\
\hline & & Compra & Venda & & \\
\hline Chapada dos & Cambará & $1.000,00$ & $1.500,00$ & 500,00 & 33,33 \\
\hline Guimarães & Cambará & 900,00 & $1.260,00$ & 360,00 & 28,57 \\
\hline Média & & 950,00 & $1.380,00$ & 430,00 & 31,16 \\
\hline
\end{tabular}




\begin{tabular}{lcrccc}
\hline Chapada dos & Teca & $1.800,00$ & - & - & - \\
Guimarães & Teca & $1.000,00$ & - & - & - \\
Média & & $1.400,00$ & - & - & - \\
\hline Cuiabá & Cedro & $1.050,00$ & $1.450,00$ & 400,00 & 27,59 \\
Média & Cedro & $1.000,00$ & $1.400,00$ & 400,00 & 28,57 \\
\hline \multirow{2}{*}{ Cuiabá } & & $1.025,00$ & $1.425,00$ & 400,00 & 28,07 \\
\hline & & 700,00 & $1.300,00$ & 600,00 & 46,15 \\
Média & Madeira mista & 850,00 & $1.200,00$ & 350,00 & 29,17 \\
& & $1.000,00$ & $1.500,00$ & 500,00 & 33,33 \\
& & 850,00 & $1.333,33$ & 483,33 & 36,25 \\
\hline Cuiabá & Jatobá & $1.200,00$ & $1.600,00$ & 400,00 & 25,00 \\
& Amescla & 700,00 & 980,00 & 280,00 & 28,57 \\
& Canelão & 950,00 & $1.100,00$ & 150,00 & 13,64 \\
& Curupichá & 950,00 & $1.100,00$ & 150,00 & 13,64 \\
& Garapeira & $1.600,00$ & $2.250,00$ & 650,00 & 28,89 \\
& Pinus & $1.000,00$ & $1.600,00$ & 600,00 & 37,50 \\
\hline
\end{tabular}

TABELA 5. Valores mercadológicos de madeiras serradas comercializadas em ambos os municípios, de acordo com a espécie florestal.

\begin{tabular}{|c|c|c|c|c|c|}
\hline \multirow{2}{*}{ Município } & \multirow{2}{*}{ Espécie } & \multicolumn{2}{|c|}{ Valores $(\mathbf{R} \$)$} & \multirow{2}{*}{$\begin{array}{c}\text { Receita } \\
\text { (R\$) }\end{array}$} & \multirow{2}{*}{$\begin{array}{c}\text { Lucro } \\
\text { (\%) }\end{array}$} \\
\hline & & Compra & Venda & & \\
\hline \multirow{3}{*}{$\begin{array}{l}\text { Chapada dos } \\
\text { Guimarães }\end{array}$} & Peroba & $1.300,00$ & $1.900,00$ & 600,00 & 31,58 \\
\hline & Peroba & $1.200,00$ & $1.900,00$ & 700,00 & 36,84 \\
\hline & Peroba & $1.380,00$ & $2.400,00$ & $1.020,00$ & 42,50 \\
\hline \multirow{5}{*}{$\frac{\text { Média }}{\text { Cuiabá }}$} & & $1.293,33$ & $2.066,67$ & 773,33 & 37,42 \\
\hline & Peroba & $1.200,00$ & $1.800,00$ & 600,00 & 33,33 \\
\hline & Peroba & $1.400,00$ & $1.700,00$ & 300,00 & 17,65 \\
\hline & Peroba & $1.100,00$ & $1.600,00$ & 500,00 & 31,25 \\
\hline & Peroba & $1.350,00$ & $1.500,00$ & 150,00 & 10,00 \\
\hline Média & & $1.262,50$ & $1.650,00$ & 387,00 & 23,48 \\
\hline \multicolumn{2}{|c|}{ Média da espécie nos municípios } & $1.275,71$ & $1.828,57$ & 552,86 & 30,23 \\
\hline Chapada dos & Itaúba & $2.200,00$ & $3.200,00$ & $1.000,00$ & 31,25 \\
\hline Guimarães & Itaúba & $1.800,00$ & $2.520,00$ & 720,00 & 28,57 \\
\hline Média & & $2.000,00$ & $2.860,00$ & 860,00 & 30,07 \\
\hline \multirow{4}{*}{ Cuiabá } & Itaúba & $2.100,00$ & $2.600,00$ & 500,00 & 19,23 \\
\hline & Itaúba & $2.300,00$ & $3.400,00$ & $1.100,00$ & 32,35 \\
\hline & Itaúba & $2.700,00$ & $3.600,00$ & 900,00 & 25,00 \\
\hline & Itaúba & $2.500,00$ & $3.500,00$ & $1.000,00$ & 28,57 \\
\hline Média & & $2.400,00$ & $3.275,00$ & 875,00 & 26,72 \\
\hline \multicolumn{2}{|c|}{ Média da espécie nos municípios } & $2.266,67$ & $3.136,67$ & 870,00 & 27,74 \\
\hline Chapada dos & Cedrinho & $1.300,00$ & $1.900,00$ & 600,00 & 31,58 \\
\hline \multirow[t]{2}{*}{ Guimarães } & Cedrinho & 980,00 & $1.500,00$ & 520,00 & 34,67 \\
\hline & Cedrinho & $1.100,00$ & $2.100,00$ & $1.000,00$ & 47,62 \\
\hline Média & & $1.126,67$ & $1.833,33$ & 706,67 & 38,55 \\
\hline \multirow{4}{*}{ Cuiabá } & Cedrinho & $1.200,00$ & $1.800,00$ & 600,00 & 33,33 \\
\hline & Cedrinho & 900,00 & $1.200,00$ & 300,00 & 25,00 \\
\hline & Cedrinho & 950,00 & $1.300,00$ & 350,00 & 26,92 \\
\hline & Cedrinho & $1.350,00$ & $1.500,00$ & 150,00 & 10.00 \\
\hline
\end{tabular}




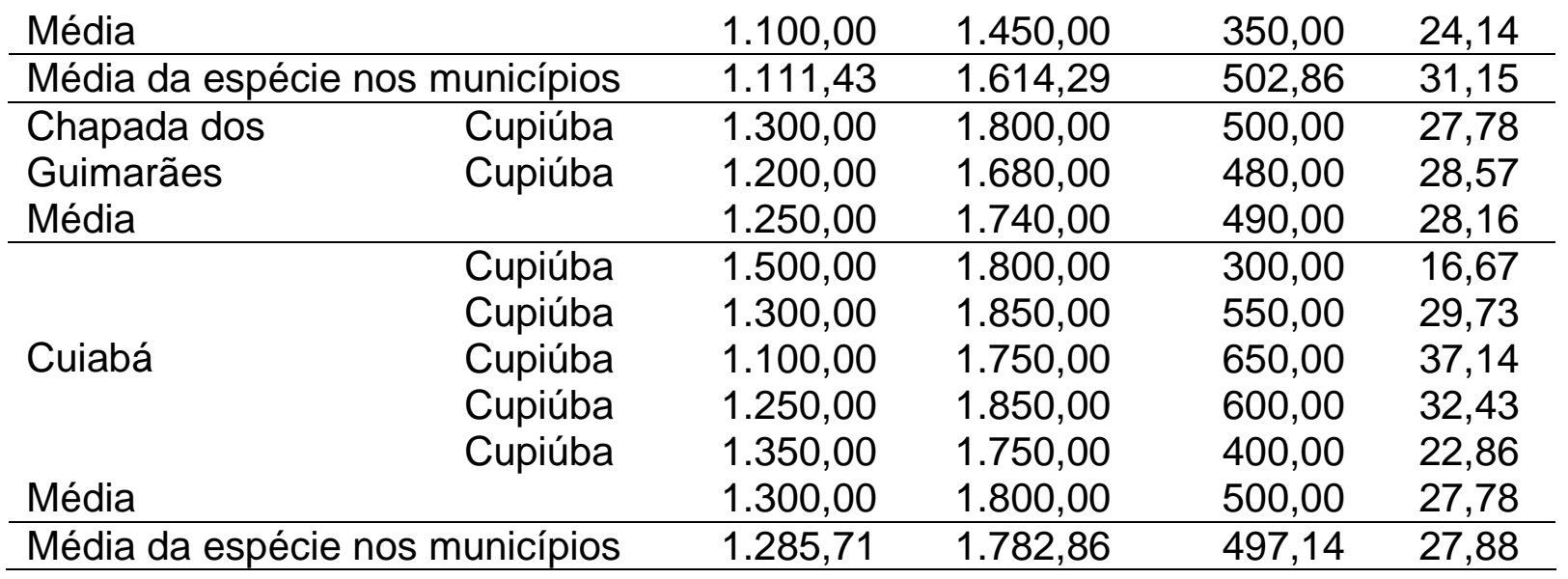

As espécies que tiveram respectivamente o maior valor médio de compra e venda foram a Itaúba com $R \$ 2.266,67$ (compra) e $R \$ 3.136,00$ (venda) e a Garapeira $\mathrm{R} \$ 1.600,00$ (compra) e $\mathrm{R} \$ 2.250,00$ (venda). A Teca apresentou um alto valor médio de compra ( $R \$ 1.400,00)$, porém essa espécie não teve valor de venda informado pelos estabelecimentos comerciais, uma vez que os mesmos não vendem a madeira serrada de teca para terceiros, eles compram das serrarias para confecção de seus próprios móveis, que são comercializados dentro do estabelecimento. Nessa situação, há uma agregação de valor à madeira, o que lhes rende mais lucro, pois os entrevistados vendem os móveis de teca, que são produzidos sob encomenda. Essas espécies de maior valor comercial, estavam presentes em $90 \%$ das empresas entrevistadas, sendo a Itaúba a mais frequente (60\%) e a garapeira e a teca apareceram em uma frequência menor, respectivamente em $10 \%$ e $20 \%$ dos estabelecimentos.

As espécies madeireiras com menor valor médio de compra e venda respectivamente foram atribuídos para a Amescla $R \$ 700,00$ e $R \$ 980,00$, a mista (madeira reconstituída) $R \$ 850,00$ e $R \$ 1.330,00$, Curupixá $R \$ 950,00$ e $R \$ 1.100,00$, Canelão $R \$ 950,00$ e $R \$ 1.100,00$ e Cambará $R \$ 950,00$ e $R \$ 1.380,00$. Ao se comparar os dois municípios verifica-se que o maior lucro em venda de madeira serrada foi para o município de Chapada dos Guimarães (Tabelas 4 e 5). Algumas espécies se destacaram como as preferidas pelos comerciantes, como foi o caso da Peroba, Cedrinho e Cupiúba que apareceram em sete estabelecimentos dos dez entrevistados e a Itaúba que estava presente em seis dos dez estabelecimentos (Tabela 5).

Analisando-se os anos anteriores, nota-se um aumento no preço das madeiras, pois Ribeiro et al. (2016) no período de 2004 a 2010, constatou um preço $\left(R \$ / \mathrm{m}^{3}\right)$ inferior, em relação aos encontrados neste trabalho, para as espécies Itaúba ( $R$ \$ $968,00)$, Garapeira $(R \$ 791,00)$, Teca $(R \$ 1.185,00)$, Amescla $(R \$ 286,00)$, Canelão $(R \$ 286,00)$ e Cambará ( $R \$ 520,00)$. Isso provavelmente ocorreu devido à fiscalização mais efetiva dos órgãos ambientais do estado, em relação ao uso e comercialização de madeiras nativas, as quais, atualmente, deverão vir prioritariamente de plano de manejo.

\section{Principais usos das madeiras serradas}

Os principais usos para as madeiras serradas comercializadas nos dois municípios estudados encontram-se na Figura 1. 


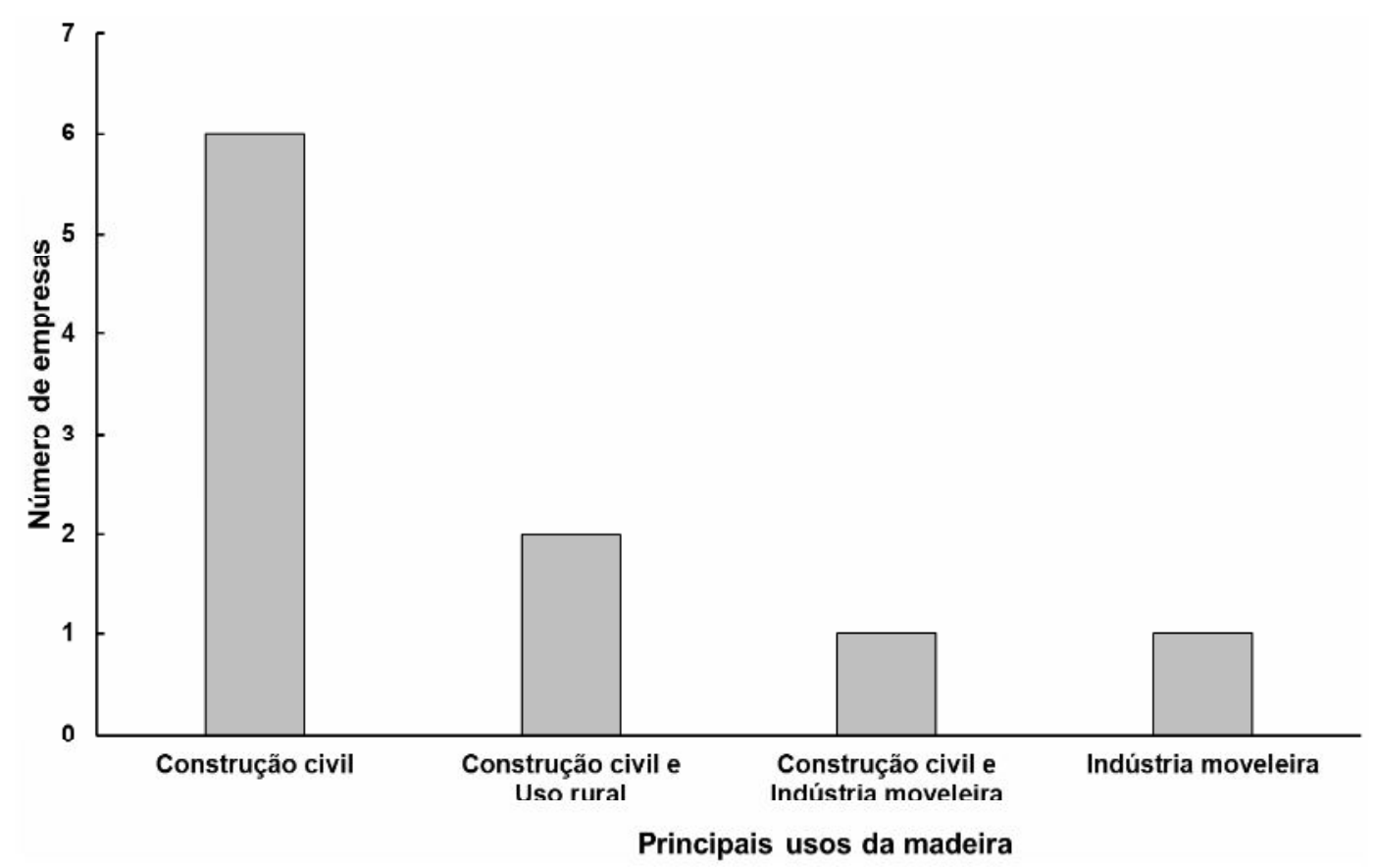

FIGURA 1. Principais usos das madeiras comercializadas em Chapada dos Guimarães e Cuiabá - MT.

Seis das dez empresas apontaram que o principal uso das madeiras que comercializam é para a construção civil. Em Cuiabá, cinco empresas informaram esse uso e em Chapada dos Guimarães somente uma. Apesar de serem madeiras nobres, vindas de espécies nativas, o uso dessas madeiras na construção civil foi informado como sendo para utilização definitiva ou temporária. De forma definitiva elas são usadas em esquadrias de portas e janelas, nas estruturas de cobertura, nos forros, pisos e rodapés. Para usos temporários, elas são empregadas prioritariamente, para delimitar os canteiros de obras, escoramentos, andaimes e fôrmas para cimento. Nesse caso, elas são usadas uma só vez, ou reutilizadas no máximo mais uma vez, e em seguida são descartadas. Isso mostra um uso inadequado para nossas madeiras nativas, que poderia ser substituído por madeiras de reflorestamento, que apresentam um ciclo de corte mais curto.

A utilização conjunta em construção civil e meio rural apareceu em duas das dez madeireiras, uma em Cuiabá e outra em Chapada dos Guimarães. Para a construção civil os usos são os mesmos dos relatados acima e para o meio rural, o uso seria para manutenção de pontes, construção de currais e também na demarcação das propriedades rurais (cercas).

O uso na indústria moveleira foi relatado em uma empresa (10\% das empresas estudadas). Esse empreendimento foi caracterizado como marcenaria e encontra-se na cidade de Chapada dos Guimarães. Seu foco principal é transformar peças de madeira em um objeto útil ou decorativo, executando cortes, encaixes e entalhes em peças, conforme pedido do cliente.

O emprego conjunto na construção civil e indústria moveleira ocorreu também em somente um estabelecimento ( $10 \%$ das empresas estudadas), localizado em Chapada dos Guimarães. Este estabelecimento fornece peças diversas para o ramo de construção civil e produz peças novas como camas, mesas, cadeiras, armários dentre outros, para o ramo moveleiro, além de realizar reformas gerais. 


\section{Tipos de resíduos gerados no reprocessamento da madeira}

empresas.

$\mathrm{Na}$ Figura 2, são apresentados os tipos de resíduos produzidos pelas

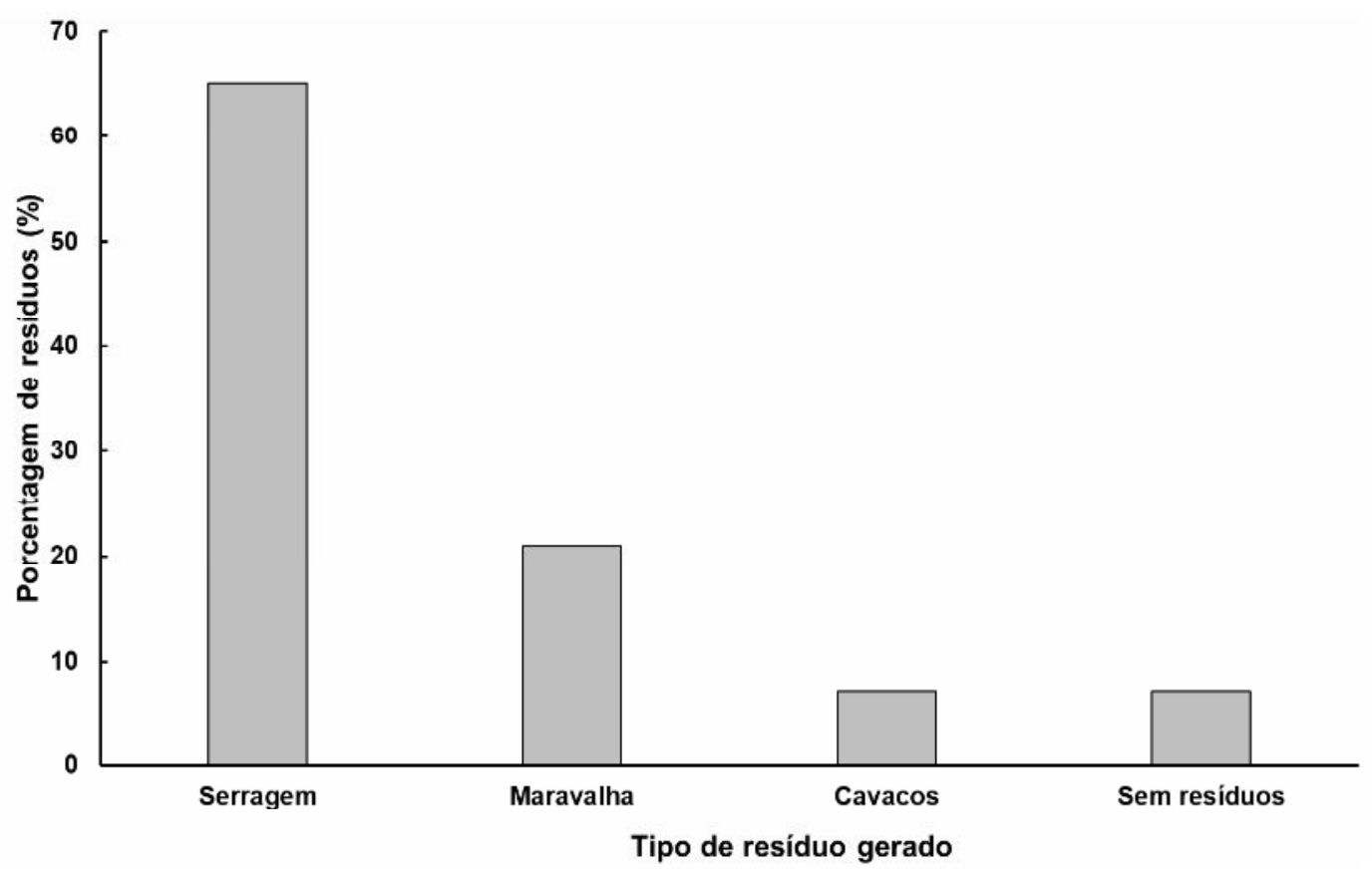

FIGURA 2. Resíduos gerados pelas indústrias madeireiras em ambos municípios.

Oito das 10 empresas realizam o reprocessamento da madeira serrada no próprio pátio do estabelecimento, e a operação mais comum foi o aplainamento das peças. Os resíduos gerados, desse processo foram serragem (pó de serra), produzida em $65 \%$ das empresas visitadas, seguidas pela maravalhas (restos de plaina) com $21 \%$, e cavacos misturados com restos de cascas, os quais foram observados em $7 \%$ das empresas. Somente $7 \%$ dos entrevistados relataram não produzir resíduos.

Segundo Melo et al. (2016), os resíduos de uma indústria madeireira são classificados basicamente em serragem (pó de serra), maravalha, cepilhos (serapilheira), cascas, cavacos e lenha (costaneiras, refilos) e sua classificação é uma maneira eficiente de proporcionar utilidade para eles. $\mathrm{O}$ autor enfatiza que para o aproveitamento dos resíduos, primeiro se classifica depois se quantifica e posteriormente se oferece as formas de aproveitamento.

A indústria madeireira apresenta baixo rendimento operacional e, por consequência, uma alta geração de resíduos, que quando não aproveitados corretamente, trazem problemas ambientais como a contaminação de rios, solos e ar, além de impactos sociais para a população (RAMOS et al., 2017).

\section{Volume de resíduo gerado}

Em relação ao volume de resíduos, verifica-se que 8 das 10 empresas analisadas, produzem menos que $25 \%$ de resíduos, uma produz entre $25 \%$ e $50 \%$, e uma desconhece a quantidade gerada. Nenhuma madeireira apresentou valores superiores a $50 \%$ de resíduos (Figura 3 ). 


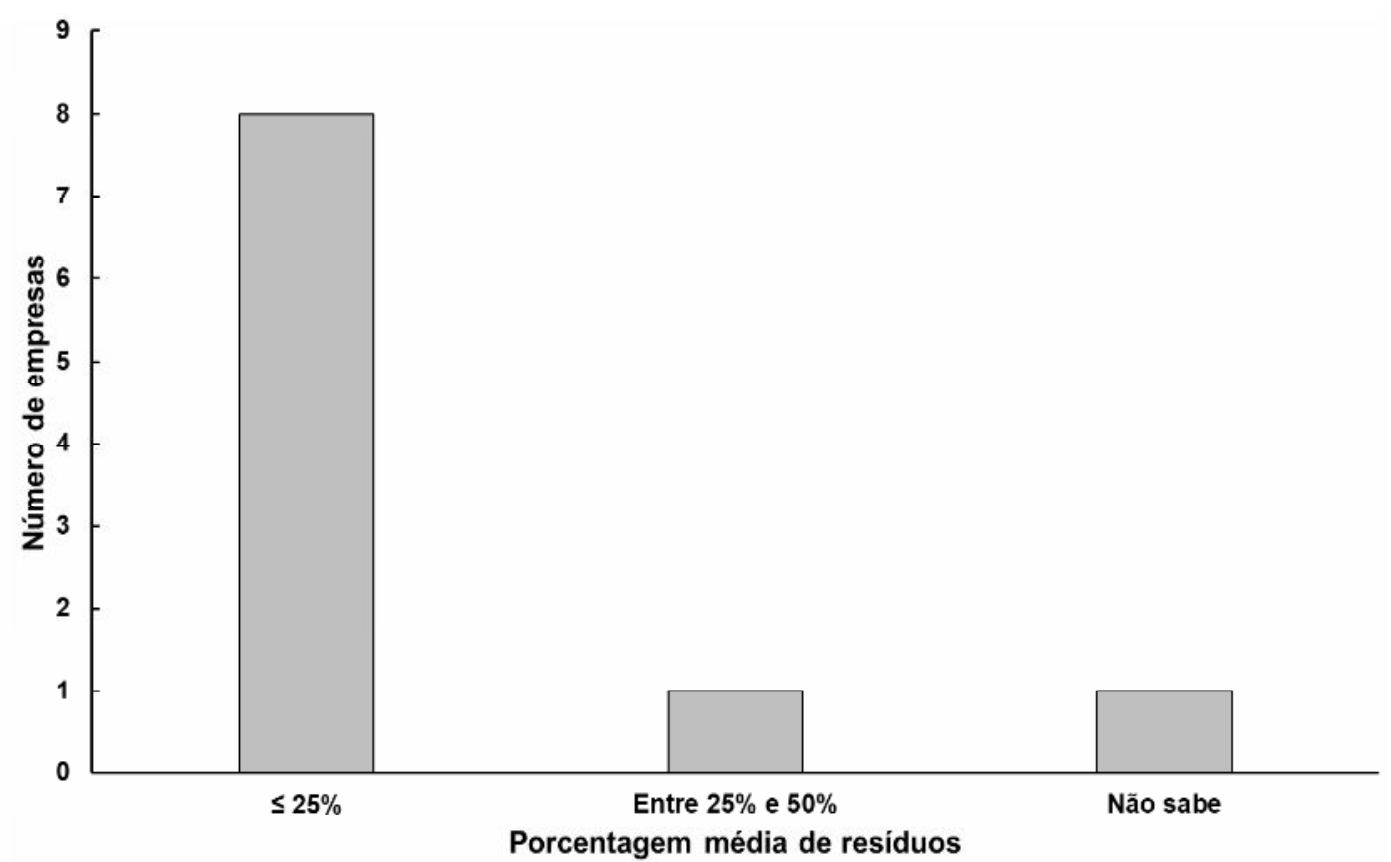

FIGURA 3. Porcentagem média de resíduos gerados pelos estabelecimentos.

As quantidades de resíduos produzidos geralmente variam de acordo com a qualificação do operador, as técnicas de desdobro realizada, o maquinário, a espécie utilizada e o produto que se deseja obter. Esses fatores, quando não estão alinhados conduzem a um alto grau de resíduo e consequentemente, a um baixo rendimento em madeira serrada (MENDOZA et al., 2017).

\section{Destinação dos resíduos}

No momento da coleta de dados foi observado que muitos dos estabelecimentos estudados tinham em seus pátios, grande quantidade de resíduos, gerando desconforto aos funcionários e até mesmo aos proprietários e clientes. Segundo os entrevistados, isto estava ocorrendo devido à dificuldade encontrada por eles, para dar um destino aos mesmos e que quando doados a terceiros, eram os próprios proprietários que arcavam com todas as despesas de retirada e transporte, o que geraria um custo adicional e poucas empresas estavam com seus pátios limpos.

Analisando-se os dados, verificou-se que $50 \%$ das empresas realizaram a venda dos resíduos para terceiros (padarias, cerâmicas, artesões), gerando assim uma pequena renda extra com esse material que não é aproveitado nos estabelecimentos, $29 \%$ doaram seus resíduos para terceiros, $14 \%$ depositaram os resíduos no pátio da empresa, e apenas $7 \%$ apontaram que não geravam resíduos (Figura 4). 


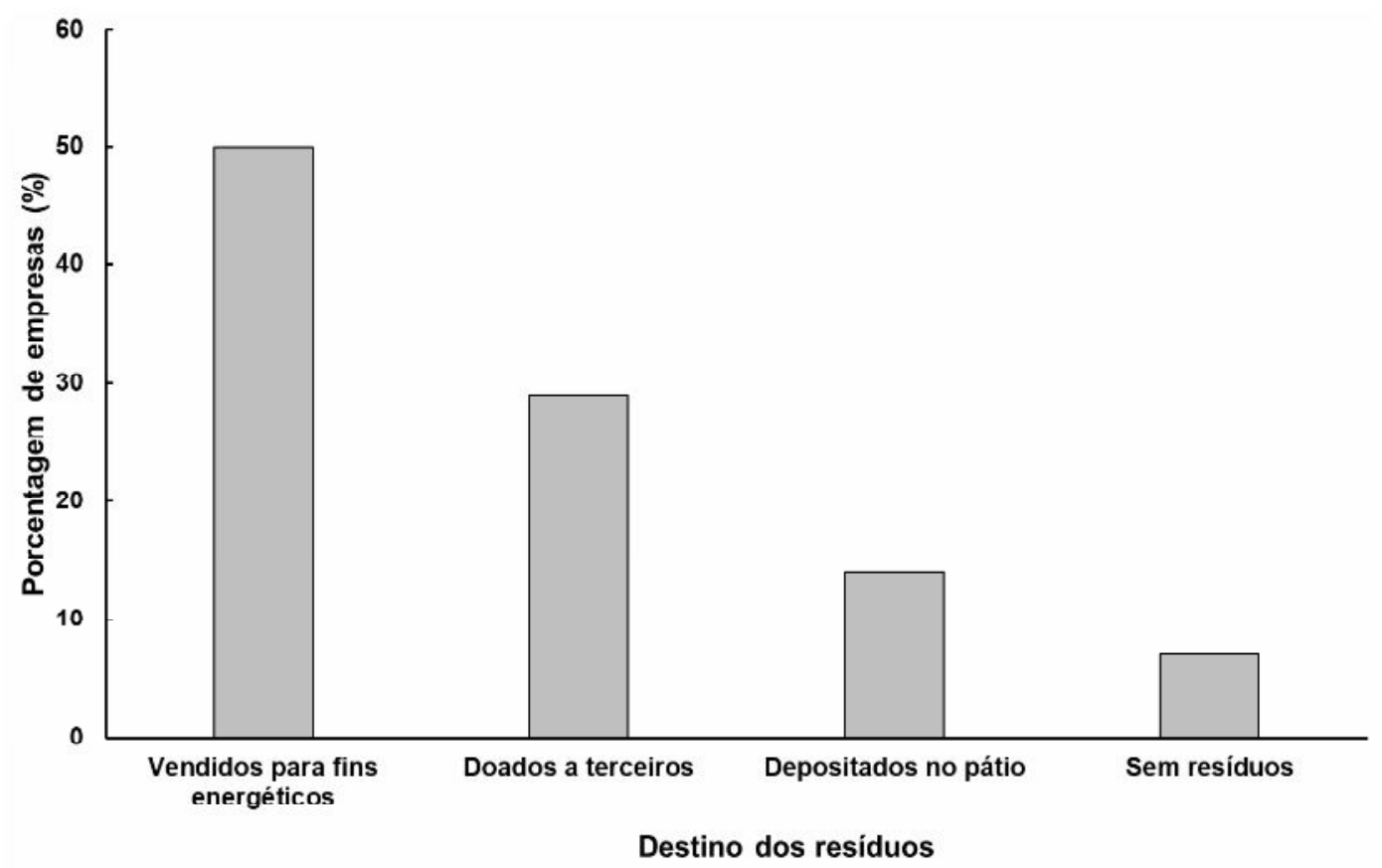

FIGURA 4. Destinação dos resíduos gerados pelas madeireiras estudadas.

Resultados semelhantes aos deste estudo foram obtidos por Cerqueira et al. (2012), em suas pesquisas com resíduos madeireiros gerados pelas serrarias do município de Eunápolis-BA. Os referidos autores constataram que 55\% das empresas vendiam seus resíduos para a geração de energia em cerâmicas próximas ao município, $17 \%$ realizavam a venda para utilização em baias de animal, $16 \%$ doavam a interessados, $8 \%$ descartavam nos lixões e $2 \%$ utilizavam para confecção de pequenos artefatos de madeira.

De acordo com Ramos et al. (2017) os investimentos em equipamentos mais eficientes, na qualificação da mão de obra e no aproveitamento dos resíduos poderiam fazer a atividade madeireira mais sustentável, diminuindo os problemas causados à população e ao ambiente. Amaral et al. (2018), corroboram com essa ideia, mostrando em suas pesquisas com aproveitamento de resíduos, a viabilidade de produção de objetos artesanais no município de Capitão Poço - PA.

\section{CONCLUSÃO}

Os perfis dos comércios de madeira serrada nos dois municípios foram semelhantes, sendo caracterizados por empresas familiares. Porém, os valores mercadológicos das madeiras oscilaram bastante de um estabelecimento para outro, independente do município. As madeiras são prioritariamente empregadas para a construção civil, indústria moveleira e uso rural, sendo as espécies Cupiúba, Peroba, Itaúba e Cedrinho as mais comercializadas e mais valorizadas. Os resíduos gerados em maior quantidade, pelo reprocessamento das madeiras, foram o pó de serra e as maravalhas, os quais eram vendidos para terceiros, que os utilizavam em artesanatos e também como coproduto para geração de energia em fábricas de cerâmicas. 


\section{REFERÊNCIAS}

AMARAL, D.; ZAÚ, A. S.; GAMA, D. C.; ALBUQUERQUE, E. SILVA, F. J. Aproveitamento de resíduo madeireiro em um município amazônico. Biodiversidade, v. 17, n.2, p. 25-32, 2018.

Disponível em:

< http://periodicoscientificos.ufmt.br/ojs/index.php/biodiversidade/article/view/7070>

CERQUEIRA, P.H.A; VIEIRA, G.C; BARBARENA, I.M; MELO, L.C; FREITAS L.C. Análise dos resíduos madeireiros gerados pelas serrarias do município de Eunápolis-BA. Revista Floresta e Ambiente. v. 19, n.4, p. 506-510, 2012.

Disponível em: <http://www.floram.org/ed/588e21eae710ab87018b4587> DOI: https://doi.org/10.4322/floram.2012.051

CIPEM - Centro das Indústrias produtoras e Exportadoras de Madeiras de Mato Grosso. Dados do Setor: volume transportado. Cuiabá, 2017.

Disponível em: <https://www.cipem.org.br/dados-do-setor/>

CONFEDERAÇÃO NACIONAL DO TRANSPORTE - CNT. Pesquisa CNT de rodovias 2018: relatório gerencial. - CNT: SEST: SENAT. 405p. Brasília, DF. 2018. Disponível em: < https://pesquisarodovias.cnt.org.br/Paginas/relatoriogerencial>.

INSTITUTO BRASILEIRO DE GEOGRAFIA E ESTATÍSTICA - IBGE. Produção da extração vegetal e da silvicultura 2016. Rio de Janeiro, 2016. 54p.

Disponível em: <https://agenciadenoticias.ibge.gov.br/>.

INSTITUTO BRASILEIRO DE GEOGRAFIA E ESTATÍSTICA - IBGE. Cidades. 2018. Disponível em: <https://cidades.ibge.gov.br/>.

MENDOZA, Z. M. S. H.; BORGES, P. H. M.; PIERIN, L. C. Coeficiente de rendimento em madeira serrada de oito espécies nativas de Mato Grosso. Nativa, v.5, esp., p.568-573, dez. 2017.

Disponível em:

<http://periodicoscientificos.ufmt.br/ojs/index.php/nativa/article/view/4430>

DOI: http://dx.doi.org/10.5935/2318-7670.v05nespa16

MELO, R. R.; ROCHA, M. J.; JUNIOR, F. R.; STANGERLIN, D. M. Análise da influência do diâmetro no rendimento em madeira serrada de cambará (Qualea $s p$.).

Pesquisa Florestal Brasileira, v. 36, n. 88, p. 393-398, 2016.

Disponível em:<https://pfb.cnpf.embrapa.br/pfb/index.php/pfb/article/view/1151/530>. DOI: https://doi.org/10.4336/2016.pfb.36.88.1151.

RAMOS, W. F.; RUIVO, M. B. L. P.; JARDIM, M. A. G.; PORRO, R.; DA SILVA CASTRO, R. M.; DE SOUZA, L. M. Análise da indústria madeireira na Amazônia: gestão, uso e armazenamento de resíduos. Revista Brasileira de Ciências Ambientais (Online), n. 43, p. 1-16, 2017.

Disponível em: 
<https://www.researchgate.net/publication/316415863_Analise_da_industria_madeir eira_na_Amazonia_gestao_uso_e_armazenamento_de_residuos>

DOI: $10.5327 / Z 2176-947820170057$

RIBEIRO, E. S.; SOUZA, R. A. T. M.; PAULA, M. H.; MESQUITA, R. R. S.; MOREIRA, E. L.; FAZION, H. Espécies florestais comercializadas pelo estado de Mato Grosso. Biodiversidade, v. 15, n. 2, p. 15-28, 2016.

Disponível em:

<http://www.periodicoscientificos.ufmt.br/ojs/index.php/biodiversidade/article/view/39 $57 / 2752>$.

SILGUEIRO, V.; VALDIONES, A. P.; CARDOSO, B. D.; THUAULT, A. Mapeamento da ilegalidade na exploração madeireira entre agosto de 2013 e julho de 2016. Cuiabá: ICV. Transparência Florestal Mato Grosso, n.6, 2018.

Disponível em:

<https://www.icv.org.br/wpcontent/uploads/2018/02/TF9llegalidadeexploracao madeireiraMT.pdf> 